\title{
How Ideological Migration Geographically Segregates Groups
}

\author{
Matt Motyl \\ University of Virginia \\ Ravi Iyer \\ University of Southern California \\ Shigehiro Oishi, Sophie Trawalter, and Brian A. Nosek \\ University of Virginia
}

Correspondence should be addressed to: Matt Motyl, Department of Psychology, University of Virginia, Charlottesville, VA 22904. Email: motyl@ virginia.edu. 


\begin{abstract}
Here, we advance the ideological migration hypothesis — individuals choose to live in communities with ideologies similar to their own to satisfy their need to belong. In Study 1, incongruity between personal and community ideology predicted greater residential mobility and attraction to more ideologically-congruent communities. In Study 2, participants who perceived their ideology to be at odds with their community's displayed a decreased sense of belonging and an increased desire to migrate. In Studies 3 and 4, participants induced to view their current community as growing more incongruent with their own ideology expressed a decreased sense of belonging and an increased desire to migrate. Ideological migration may contribute to the rise in cultural, moral, and ideological segregation and polarization of the American electorate.
\end{abstract}

Keywords: ideology, migration, social ecology, politics, residential mobility, voting behavior 


\section{How Ideological Migration Geographically-Segregates Groups}

People tend to live in communities with others who have similar racial and ethnic backgrounds, who have similar lifestyles and personalities, and who adhere to similar political and religious creeds (Dixon \& Durrheim, 2003; McPherson, Smith-Lovin, Cook, 2001; Rentfrow, Gosling, \& Potter, 2008). Recently, clustering along political lines has gained media attention as this geographic separation has led to a clear inability to find national consensus on big issues (Avlon, 2010; Greenblatt, 2012). This ideological clustering is a recent phenomenon of the past few decades (Abramowitz, 2012; Bishop, 2008), and given what psychologists know about the effects of segregation (e.g., Deutscher, 1948), this geographical division along ideological lines is a likely contributing factor to the partisanship and rancor that is currently paralyzing the United States' government (Burr, 2013). How these homogeneous communities emerge is unclear. The present paper suggests that this de facto segregation might emerge as people strive to satisfy basic human needs.

One possible explanation for the emergence of these homogeneous enclaves is that people are "born into it". This is easy to understand with racial composition; racial enclaves can emerge via reproduction across generations. It is also conceivable with personality and ideology. Personalities and ideologies are shaped by the cultures - macro and micro - that people inhabit (Markus \& Kitayama, 1991). Each of these possibilities proposes that environments affect their inhabitants. But, the reverse causation may also occur. People may also change their environments. People with certain racial identities, personalities, and ideologies may feel like their basic needs are not being met in one residence, so they could choose to change residences to better satisfy these needs. For example, following social rejection and institutional persecution, the Pilgrims sailed the Mayflower across the Atlantic Ocean in pursuit of a home 
where they felt that their religious values would be accepted (Philbreck, 2007). This extreme example illustrates the idea that people may leave places where they feel incapable of satisfying basic psychological needs, like the need to belong (Baumeister \& Leary, 1995). This may also help explain why people in certain occupations are migrating to communities where many of the residents have similar occupations (Florida, 2008) and people with certain personality traits are migrating to communities where many residents have similar traits (Rentfrow et al., 2008). Consistent with the idea of ideological migration, we are increasingly seeing communities segregated by ideology as well (Abramowitz, 2012; Bishop, 2008).

In the present article, we provide evidence that perceptions of fitting in with the ideological composition of communities may motivate both moving away from those that are incongruent and moving toward those that are congruent with one's own ideologies. The longterm consequence is a gradual construction of segregated and polarized ideological enclaves, rather than this occurring exclusively via reproduction and cultural indoctrination.

\section{Migration}

Roughly half of the population changed their residence between 1995 and 2000 (Schmitt, 2001) and an estimated 40-50 million Americans move each year (Florida, 2008). Understanding how people make these residential migration decisions is complex (Greenwood, 1985; Oishi, 2010). Employment, family, finances, personality, and temperament all influence migration (Jokela, 2009; Jokela, Elovainio, Kivimaki, \& Keltikangas-Jarvinen, 2008; Winstanley, Thorns, \& Perkins, 2003). People likely make these decisions in ways that help them pursue their goals. For example, experts in particular occupations tend to move to communities seeking such specialists (Florida, 2004), and extroverts may move to communities with more sociallystimulating environments (Furnham, 1981). In these cases, the migrants may be assuming that 
the residents living in their destination communities are similar to them in some important ways, as people generally are attracted to similar others (Byrne, 1971). Certain types of similarity may be more attractive than others. For example, moral value similarity is more important in selecting others as friends (Haidt, Hom, \& Rosenberg, 2003), teammates in the workplace (Guillaume, Bridbock, \& Ricketta, 2012), and neighbors (Putnam, 2007). So, an influence on migration may be seeking environments where are there more similar others on specific important characteristics such as lifestyle, values, and political ideology (Byrne, Clore, \& Smeaton, 1986; Karylowski, 1976; Werner \& Parmelee, 1979).

A complementary possibility is that people move away from communities based on feeling repulsed by the preponderance of dissimilar others (Rosenbaum, 1986). People may migrate when they feel they do not belong in their current community. In some cases, people may find the ideology of their current community disgusting, ideologically-objectionable, or threatening, eliciting unpleasant existential anxiety (Crawford, 2012; Haidt \& Graham, 2007; Motyl, Vail, \& Pyszczynski, 2009; Schimel, Hayes, Williams, \& Jahrig, 2007). When coping with these aversive states, people's natural reaction involves trying to reduce the aversive state. When evaluating residential options, people may be especially inclined to move away from communities with ideologies that are incongruent with their own.

People desire communities where they share a worldview with their neighbors, allowing for a shared understanding of social life and binding people together into sacred groups that may help them to feel like something greater than a single mortal being (Motyl et al., 2011;

Pyszczynski, Greenberg, \& Solomon, 1997; Vail et al., 2009). Cultures lacking sufficient social integration displayed higher suicide rates than those with sufficient social integration (Durkheim, 1897). In recent evidence, the suicide rate in states that voted for President Obama with a 
significant minority supporting the losing candidate (here, Senator McCain) had higher suicide rates than states where the vote heavily favored either President Obama or Senator McCain (Classen \& Dunn, 2010). One interpretation of this finding is that states with more singular values are more socially integrated and, even if a state voted in favor of a losing candidate, the residents can take solace by providing each other social support. In states where a sizable minority of the population voted for the losing candidate, there may be less social integration, leading to elevated suicide rates. Fortunately, suicide is rare and the vast majority of people living in communities with values incongruent with their own values do not commit suicide. There are, however, other negative consequences of feeling a lack of belonging. For example, in the presence of Christian symbols, non-Christians exhibit reduced subjective well-being. This reduction in subjective well-being was mediated by the sense that they did not belong in that setting (Schmitt, Davies, Hung, \& Wright, 2010). Lacking a sense of belonging appears also to impair academic and athletic performance, mental and physical health, and civic and political participation (Anderson, 2009; Leary, 2009; Major \& O’Brien, 2005; Putnam, 2000; Sheldon \& Bettencourt, 2010; Walton \& Cohen, 2011). Some people have a means to resolve a lack of ideological fit between person and community; they can pack up and move.

In sum, perceived similarity with communities may lead people to migrate away from dissimilar communities and toward similar communities. In the current research, we propose the ideological migration hypothesis - individuals that have the flexibility to do so will tend to choose communities with ideological worldviews similar to their own to satisfy their need to belong. From this hypothesis, we develop three key predictions: (a) misfit between the person's and the community's ideological worldviews will engender increased migration; (b) fit between 
the person's and prospective community's ideological worldviews will influence where people choose to migrate; and, (c) this migration motivation will be driven by people's need to belong.

\section{Ideology and Migration}

Community-level data provide preliminary support that people are migrating away from ideologically misfit communities and toward ideologically fit ones. For example, communities are growing more morally and politically homogeneous (Bishop, 2008; Bishop \& Cushing, 2008). These aggregate-level data, though, do not clarify the psychological processes contributing to migration. The correlational, aggregate community data do not, for example, address the possibility that the moral values of the majority group in a given community are gradually adopted by the minority group through social influence (Asch, 1956; Cialdini \& Goldstein, 2004; Festinger, 1963; Harton, \& Bullock, 2007; Latane, 1981; Sinclair, Lowery, Hardin, \& Colangelo, 2005).

While social influence may have an impact on worldviews, we believe that some part of the explanation for the correlation is that people perceive an ideological misfit with their own community and select new communities that are a better ideological fit. How people identify the ideological matrix of a community is unclear. Historically, people have not been particularly knowledgeable about the moral and political values of their communities (Converse, 1964; DelliCarpini \& Keeter, 1996), but this may be changing as Americans seem to be growing increasingly ideological (Jost, 2006). Discerning between ideological communities may have grown easier over recent decades, as ideological identities have become more expansive to include not just political party membership, but also beliefs about human nature, attitudes, religious denomination, and personality (Abramowitz, 2012; Caprara, Barbaranelli, \& Zimbardo, 1999; Jost, Glaser, Sullaway, \& Kruglanski, 2003; Tomkins, 1965). Drawing on contemporary 
and historical political theories (e.g., Burke, 1790/2003, Mill, 1859/2003; Sowell, 2007), ideological orientation can be viewed as a simple, proxy indicator of many variables, including a person's broader non-political worldview. Ideology predicts variation in moral foundations, and these foundations predict partisan identification, political attitudes, policy preferences, and voting behavior (Graham et al., 2011; Inbar, Pizarro, Iyer, \& Haidt, 2011; Iyer et al., 2010; Koleva, Graham, Iyer, Ditto, \& Haidt, 2012). People with liberal ideologies prioritize individualism and protecting individuals from injustice. In contrast, people with conservative ideologies prioritize group cohesion and orthodoxy. Perhaps liberal and conservative communities have physical characteristics that convey different ideological identities.

At the individual level, for example, people with liberal and conservative ideologies construct their bedrooms and offices by displaying different types of decorations and organizing their possessions in distinct ways (Carney, Jost, Gosling, \& Potter, 2008). It is unlikely that people have the capability to decorate and organize their broader community in this way, but community characteristics may vary according to the dominant ideology of that community. Communities with liberal ideologies do tend to have more organic food markets, bicycle trails, and a greater proportion of hybrid automobiles on the road (Chinni \& Gimpel, 2004). In contrast, communities with conservative ideologies do tend to have more "big box" stores, a higher gun store-to-bookstore ratio, and a greater proportion of sport utility vehicles on the road. It is possible that these characteristics enable people to discern the ideological leanings of communities.

\section{The Present Studies}

We tested the ideological migration hypothesis using four different methods and samples. In Study 1, with a large sample of liberals and conservatives, we found evidence that participants 
who had resided in a community that was misfit with their own ideological identities were disproportionately likely to migrate, and that their new locations better fit their ideological worldviews. In Study 2, with a different large sample of liberals and conservatives, we found evidence that people who perceived their community as not fitting with their own ideological worldviews expressed a greater desire to migrate. Furthermore, Study 2 demonstrated that the relationship between perceived ideological fit and the desire to migrate was fully mediated by sense of belonging. In Study 3, with a university sample of liberals and conservatives, we found experimental evidence that participants led to think that their university was becoming less fitting with their ideological worldview expressed a greater desire to transfer. Again, the effect of perceiving ideological fit on the desire to transfer was fully mediated by sense of belonging. In Study 4, we experimentally manipulated participants' ideology and replicated the effects from Study 3, showing that ideological fit is important, even for people with experimentally-assigned ideologies.

\section{Study 1: Ideological Migration in Big Data}

\section{Participants}

Participants were 1,010,008 U.S. residents (58\% female, $42 \%$ male) who visited the Project Implicit website (http://implicit.harvard.edu/) between December 15, 2006 and May 10, 2010 and volunteered to take an Implicit Association Test (IAT; Greenwald, Schwartz, \& McGhee, 1998) examining implicit preference for different presidents $(n=191,695)$, presidential candidates $(n=76,672)$, racial groups $(n=465,295)$, or sexual orientations $(n=276,809) .{ }^{1}$ Only the participants' demographic reports from these data collections, including postal codes, were relevant for the current purposes. Data collection at Project Implicit is continuous. The date range and data were selected to be sufficiently large to ensure high precise estimation of effects. 
Participants ranged in age from 18 to $90(M=35.23, S D=12.57)$ and was politically diverse (25\% conservative, $25 \%$ neutral/moderate, and $50 \%$ liberal). The sample included residents of all 50 states and Washington, D.C. ( $n$ s ranged from 1,973 in Wyoming to 119,644 in California). ${ }^{2}$

\section{Materials and Procedure}

Participants completed an IAT, a brief questionnaire related to the topic of the IAT, and a short demographic questionnaire in a random order. For this study, we used only three items from the demographic questionnaire: self-reported political orientation on a 7-point Likert-type item ranging from 1 (Strongly Conservative) to 7 (Strongly Liberal) with the midpoint 4 (Neutral), the zip code where they resided for the greatest length of time, and the zip code of their current residence. Only participants who responded with interpretable data for all three items were included in the analyses. ${ }^{3}$

To estimate the ideological climate of participants' prior and current communities, we combined these data with Riskind and Motyl's (2012) social climate database drawn from the 2010 census and other sources. The social climate database included the census zip code tabulation area ${ }^{4}$ voting percentage for President Obama in the 2008 Presidential election ${ }^{5}$.

\section{Results}

\footnotetext{
${ }^{2}$ We only included participants in this sample who had not previously completed an IAT or other study on the Project Implicit website.

${ }^{3}$ Most participants provided other demographic information, too. While these demographic variables do predict migration, they are not central to the current hypotheses and, when controlling for these variables, the pattern of effects presented in the results section do not change. See supplementary materials for these analyses.

${ }^{4}$ Zip Code Tabulation Areas (ZCTAs) are slightly different from Zone Improvement Plan (ZIP) codes. ZCTAs correspond to census block boundaries but ZIP codes do not. Therefore, the government only has information on resident demographics at the ZCTA and not ZIP code level. There is considerable overlap between ZCTAs and ZIP codes, but some vary slightly (see US Census Bureau ZIP Code Tabulation Area, 2012). This variation introduces some error into the present data making relationships harder to detect.

${ }^{5}$ In recent decades, voting preferences of communities are quite stable. Across Presidential elections, the vote percentage for the Democratic or Republican candidates correlates at .90 or higher (see Abramowitz, 2012). Given this stability, data from any recent election should result in very similar findings. Furthermore, community vote percentage for President Obama correlated almost perfectly negatively with vote percentage for Senator McCain $(r=$ $.99)$.
} 


\section{Data Preparation}

Participants were divided into two groups - those who had moved and those who had not. Movers were those who reported different current and longest-lived zip codes. This means that non-movers included people who had moved previously, but who have lived longer in their current zip code than in any other - i.e., a stable resident for our purposes. Also, in a small percentage of cases, zip codes could have changed without the person moving. However, this is rare and unlikely to affect the present analyses in any systematic way. Of the 1,010,008 participants, 589,879 (58\%) of them reported having moved to a different zip code by this criterion.

\section{Do people who have values different from those of their communities show a greater}

\section{likelihood of moving to a new community?}

We first tested whether ideological fit predicted moving to another community. To do so, we conducted a hierarchical logistic regression. In the first step, we entered participant age, education, gender, and race, and community population, rural-urban commuting score, population, per capita income, percent of residents who are white, and percent of residents who hold at least a bachelor's degree. ${ }^{6}$ In the second step, we regressed migration $(0=$ did not migrate, 1 = migrated) on the participants' political orientation, community vote percentage for Senator McCain, and the interaction term between these two variables retaining their rational zero points (i.e., the rational zero point for each variable indicates the variables conceptual midpoint; for political orientation, "Independent/Moderate" is the conceptual midpoint, and for

\footnotetext{
${ }^{6}$ Men and older participants were slightly less likely to have reported different zip codes. More educated participants were more likely to have migrated. White participants were more likely to have migrated than black participants. The percent of white people living in the participants' previous zip code predicted a decreased likelihood of having migrated. The percent of people living in the participants' previous zip code who held at least a bachelor's degree predicted a slightly decreased likelihood of having migrated. Population of and per capita income in the participants' previous zip code did not predict likelihood of migration. For coefficients, see supplementary materials.
} 
community vote percentage for Senator McCain, $50 \%$ is the conceptual midpoint). ${ }^{7}$

Conservatives were less likely to migrate than liberals, $B=-.31, S E=.002$, Wald $=13889.39, p$ $=5.13 \times 10^{-7}, \operatorname{Exp}(B)=0.69,95 \% \mathrm{CI}=0.687$ to 0.693 . For every unit increase in conservatism, there was a $31 \%$ decrease in the log odds of moving. Further, people living in zip codes with higher vote percentages for Senator McCain were less likely to migrate than people living in zip codes with lower vote percentages for Senator McCain, $B=-.09, S E=.003$, Wald $=966.71, p<$ $1.0 \times 10^{-7}, \operatorname{Exp}(B)=0.91,95 \% \mathrm{CI}=0.86$ to 0.96 . For every vote percent increase in support for Senator McCain, there was an $8.5 \%$ decrease in the odds of moving. Lastly, there was a significant interaction between political ideology and vote percentage for Senator McCain, $B=$ $.37, S E=.002$, Wald $=24656.90, p<1.0 \times 10^{-7}, \operatorname{Exp}(B)=0.69,95 \% \mathrm{CI}=0.685$ to 0.696 . This effect accounted for about $11 \%$ of the variability in migration behavior, Nagelkerke's $R^{2}=.11$ (see Figure 1). To decompose this interaction, we ran separate logistic regressions predicting the odds of migration from the community vote percentage for Senator McCain for each of the seven political ideologies (see Table 1). As predicted, as the community vote percent for Senator McCain increased, conservatives show decreased odds of migrating and liberals show increased odds of migrating. By contrast, as the community vote percent for Senator McCain decreased, liberals show decreased odds of migrating and conservatives show increased odds of migrating. Community vote percentage for Senator McCain was more predictive of migration for people who were more extremely liberal or conservative than for people who leaned slightly toward liberal or conservative, or people who identified as "neutral/moderate."

\footnotetext{
${ }^{7}$ As these data rely on data from individuals living in geographic clusters (zip codes), we considered using multilevel modeling. However, the samples from most clusters were very small. The sample sizes per zip code ranged from 1 to 1116 , with a mode of 3 . Furthermore, there was no relationship between observations within each cluster (intraclass correlation <.001). Thus, the parameter estimates in the logistic regression are not biased by any nesting of these data. Furthermore, the multilevel random coefficient modeling yielded the same results as the single-level logistic regression.
} 


\section{Do migrants move to communities more aligned with their morality?}

We next examined whether migration predicts increased alignment between personal and community moral values. As predicted, among participants who migrated, their personal political orientation was more strongly associated with the percent of the vote President Obama received in their current community, $r(589879)=.252, p<1.0 \times 10^{-7}(95 \%$ CI: .250 to .254$)$, than with the percent of the vote President Obama received in their prior community, $r(589879)=-.01, p=$ $4.0 \times 10^{-6}$ (95\% CI: -.012 to -.008; difference between correlations, $z=145.30, p<1.0 \times 10^{-7}$ ).

\section{Discussion}

Partisan participants who lived in communities with values different from their own were more likely to migrate than those who lived in communities with values similar to their own. Further, among those who migrated, personal ideology was more strongly associated with the new community's political ideology than their prior community's political ideology.

The likelihood of migration was particularly large among strong liberals and strong conservatives. About $80 \%$ of participants living in ideologically misfit communities moved, whereas only about $50 \%$ of participants living in ideologically fit communities did so. Further, moderates did not show a particular tendency to move into moderate communities. If anything, they were less likely to migrate at all, suggesting that ideological fit was not relevant to their decisions about migration.

The most critical limitations of these data are that they are correlational and retrospective. An obvious alternative explanation is that personal ideologies change to align with one's present community rather than leading them to move to that community. We cannot rule this out completely, but this alternative explanation is undercut by the data pattern of likelihood of migration based exclusively on previous community. If personal ideology shifted to align with 
the current community, why would current ideology predict the likelihood of having moved from the prior community in the first place? Nonetheless, it would be useful to have evidence that is not open to the reverse causal scenario. In addition, Study 1 does not provide information regarding any psychological mechanism underlying the link between misalignment of ideological values and migration. We address the limitation of the retrospective nature of Study 1 and the lack of psychological mechanism in Study 2. We will address the causal direction issue in Studies 3 and 4.

\section{Study 2: Perceiving a Lack of Ideological fit Increases Migration Desires}

Study 2 explores potential psychological mechanisms that might underlie this ideological migration effect. Specifically, Study 2 tests the degree to which participants can accurately infer their community's ideological identity and the degree to which that community identity aligns with their personal ideologies. We hypothesized that perceiving ideological fit may foster a sense of belonging and that people are less likely to move when their need to belong is satisfied. In contrast, if people perceive that their communities hold ideological identities at odds with their own, they will not feel a sense of belonging and this will inspire them to seek out a different community that might better satisfy their need to belong.

\section{Method}

\section{Participants}

Participants consisted of 1236 people residing in the United States (48\% female, 52\% male) who registered with the research website YourMorals.org. Over 99\% of participants used unique IP addresses to access this study and no IP address was used more than twice by participants in this study, indicating that participants came from separate physical locations. During the registration process, participants complete a brief demographics questionnaire. After 
registering, participants who elected to complete the "Community Preferences Questionnaire" study were directed to the present study. The items used in the present analyses were identified opportunistically from a different project being conducted on that website in the spring of 2012; the other measured variables in that project were not analyzed and are available upon request from the authors. Participants ranged in age from 18 to $88(M=42.15, S D=16.07)$ and political orientation from Very Liberal to Very Conservative (251 Very Liberal, 438 Liberal, 175 Slightly Liberal, 159 Moderate, 66 Slightly Conservative, 94 Conservative, 53 Very Conservative). Participants received no compensation for completing the study, but did receive feedback on how their scores compared to other liberals and conservatives.

\section{Materials and Procedure}

The “Community Preferences Questionnaire” study asked participants how desirable different features of communities were (e.g., the presence of many bookstores, Wal-Marts, a disproportionate number of hybrid cars on the road). Those data were collected for a different project and were not included in the present analyses. Within that study, however, participants read two statements ("I feel like I belong in my current city/town," and "I would like to live somewhere else.") and indicated their agreement on a scale from 1 (Strongly Disagree) to 6 (Strongly Agree). Then, participants estimated the percentage of residents in their current city/town who share the same basic political values as them, using a slider scale ranging from 0 to $100 \%$. This estimate served as a measure of perceived ideological fit; higher scores reflected greater ideological fit. Participants also reported their zip code and the duration of time that they lived in that zip code. All of the items in this questionnaire were presented in a random order. We used voting percent for President Obama in 2008 to determine actual ideological fit with 
their current community using the same social climate database from Study 1 (Riskind \& Motyl, 2012).

\section{Results}

\section{Is ideological misfit between self and community associated with a greater desire to move to a new community?}

First, we examined the relationship between ideological fit and desire to move by conducting a simultaneous linear regression including political ideology, the 2008 vote percent for President Obama in their current community, and the interaction between these two variables, standardized with their rational zero points retained, on the desire to migrate. Together, these variables significantly predicted desire to migrate, $F(3,1232)=16.68, p<1.0 \times 10^{-7}$, and accounted for about $4 \%$ of the variation in responses, $R^{2}=.04$.

To assess the individual contributions of each of the predictors, we examined the $t$-ratios for each. Liberalism predicted the desire to migrate, unstandardized $B=.14, S E=.04, t=4.01, p$ $=2.2 \times 10^{-5}, s r^{2}=.014$. Replicating Study 1 , more liberal respondents reported a stronger desire to move than more conservative respondents. The percent of residents voting for President Obama in the community was not related to the desire to migrate, unstandardized $B=-.01, S E=$ $.005, t=-1.68, p=.09, s r^{2}=.003$. Furthermore, there was the predicted significant interaction between political orientation and vote percent for President Obama, unstandardized $B=.26, S E$ $=.06, t=4.27, p=2.3 \times 10^{-5}, s r^{2}=.016$ (see Figure 2). Simple slopes analyses reveals that, consistent with our hypotheses, as the percentage of residents voting for Obama increased, liberals' desire to migrate decreased, unstandardized $B=-.27, S E=.03, t=-3.99, p=3.1 \times 10^{-5}$, 
and conservatives' desire to migrate increased, unstandardized $B=.25, S E=.03, t=4.08, p=$

$2.9 \times 10^{-5} .89$

\section{Perceived ideological fit is associated with actual ideological fit}

In these data, actual fit is determined using the percent of people voting for President Obama in the participants' communities of residence. This could differ from the extent to which a person perceives that their community fits with their personal ideology. If perceived ideological fit reflects actual ideological fit, then we should see a positive correlation between perceived fit and vote percentage for President Obama among liberals, and a negative correlation between perceived fit and vote percentage for President Obama among conservatives. Indeed, for liberals, perceived ideological fit with one's current community positively correlated with the percent of people voting for Obama in their past community slightly $(r(896)=.24 ; 95 \% C I=.18$ to .30$)$ and their current community strongly $(r=.62 ; 95 \% C I=.56$ to .68$)$. For conservatives, perceived ideological fit with one's current community negatively correlated with the percent of people voting for President Obama in their past community slightly $(r(190)=-.15 ; 95 \% C I=-$ .03 to -.27$)$ and their current community more strongly $(r(190)=-.37 ; 95 \% C I=-.23$ to -.49$)$. This shows that (a) perceived fit and actual fit are related, and (b) that fit is stronger comparing with one's current community than one's prior community, as expected (see Table 3 for correlations between these variables).

\section{Perceived ideological fit is associated with the desire to migrate}

\footnotetext{
${ }^{8}$ These effects persist even when controlling for the participants' duration of residence at their current zip code. Duration of residence was a small predictor of reduced desires to migrate and increased sense of belonging, accounting for about $1 \%$ of the variance for each of these outcome variables.

${ }^{9}$ Examination of results within sub-groups indicated that these relationships were consistent across groups. The interaction between political orientation and vote percent for President Obama was significant for men $(B=-.11, p=$ $.03)$ and women $(B=-.19, p=.003)$, younger $(B=-.14, p=.01)$ and older participants $(B=.15, p=.01)$, and those above midpoint on self-perceived socioeconomic status $(B=-.24, p=.001)$. The only exception was the lower SES group. The predicted interaction was not significant for those below the midpoint in socioeconomic status $(B=-.05$, $p=.35$ ), despite a similar, albeit less steep, pattern of slopes as those among participants above the SES midpoint.
} 
To test whether perceived ideological fit and political orientation predicted desire to migrate, we conducted a hierarchical linear regression with perceived ideological fit and political orientation in the first step and the interaction term between them in the second step. The overall regression including perceived ideological fit, political orientation, and their interaction was statistically significant, $R^{2}=.08, F(3,1232)=36.54, p<1.0 \times 10^{-7}$. Together, these predictors explained $8 \%$ of the variance in people's desire to migrate.

To examine the contributions of the individual predictors, we examined the $t$-ratios for each. In the first step, we found that perceived ideological fit predicted desire to migrate (unstandardized $B=-.02, S E=0.003, t=-7.03, p<1.0 \times 10^{-7}, p r^{2}=.04$ ). Specifically, the more people perceived misfit with their community, the more they wanted to migrate. Liberalism predicted increased desires to migrate, but accounted for substantially less variance (unstandardized $B=.06, S E=0.03, t=2.12, p=.03, p r^{2}=.004$ ). There was no interaction between perceived ideological fit and political orientation, (unstandardized $B=-.06, S E=0.05, t$ $=-1.20, p=.23, p r^{2}=.00$ ). That is, regardless of participants' political orientation, perceived misfit was associated with greater desire to move out of the current community.

\section{Perceived ideological fit predicts feelings of belonging}

Next, we tested whether perceived ideological fit and political orientation predicted how much participants felt like they belonged in their communities. We first conducted a hierarchical linear regression with ideological fit and political orientation in the first step and the interaction term between them in the second step. The overall regression was statistically significant, $R^{2}=$ $.19, F(3,1232)=94.64, p<1.0 \times 10^{-7}$. Together, these predictors explained $19 \%$ of the variance in people's belonging scores. 
To examine the contributions of the individual predictors, we examined the $t$-ratios for each of the regression slopes. In the first step, perceived ideological fit predicted a greater sense of belonging $\left(B=-.41, S E=0.028, t=14.04, p<.001, p r^{2}=.16\right)$. Liberalism predicted a slightly reduced sense of belonging (unstandardized $B=-.07, S E=0.03, t=2.46, p=.01, p r^{2}=.004$ ). These ratios suggest that the greater ideological fit people perceive in their community, the more they feel like they belong in that community.

In the second step, we observed a significant interaction between perceived ideological fit and political orientation, (unstandardized $B=.13, S E=0.05, t=2.48, p=.01, p r=.004, \Delta R^{2}=$ .01). Simple slopes analyses reveal that ideological fit had a slightly larger effect on liberals' sense of belonging (unstandardized $B=.94, S E=.04, t=14.02, p<.001$ ) relative to conservatives' sense of belonging (unstandardized $B=.69, S E=.04, t=11.55, p<.001$ ). Importantly, this interaction effect accounts for considerably less variance than the main effect of ideological fit on sense of belonging $\left(R^{2}=.01\right.$ vs. $\left.R^{2}=.16\right)$.

\section{Sense of belonging mediates the relationship between ideological fit and desire to migrate}

To test the possibility that sense of belonging mediates the relationship between perceived ideological fit and personal ideological orientation on the desire to migrate, we conducted a mediation analysis following Baron and Kenny's (1986) recommendations. This method is among the most conservative tests of mediational hypotheses (see Judd \& Kenny, 2010; MacKinnon, Fairchild, \& Fritz, 2007). First, a regression analysis confirmed the effect of ideological fit on sense of belonging, unstandardized $B=-.43, S E=0.028, t=-14.48, p<.001$, $p r^{2}=.17$. A second regression confirmed the effect of ideological fit on the desire to migrate, unstandardized $B=.26, S E=0.03, t=8.30, p<.001, p r^{2}=.07$. Finally, a regression including ideological fit and sense of belonging predicting the desire to migrate showed that ideological fit 
was no longer a significant predictor of the desire to migrate (unstandardized $B=.02, S E=.03, t$ $=0.81, p=.42$ ), while the hypothesized mediator, sense of belonging, remained a significant predictor (unstandardized $B=-.56, S E=.03, t=-19.40, p<.001$ ). Sobel's significance test for mediation supported this hypothesis, Sobel's $z=-14.19, p<.001$. See Figure $3 .{ }^{10}$

\section{Discussion}

Study 2 provides correlational evidence supporting our hypothesis that a perceived lack of ideological fit reduces one's sense of belonging that, in turn, increases one's desire to migrate. Also, the findings show that perceptions of ideological fit are related to actual ideological fit - at least as indexed by political support for Democratic versus Republican presidential candidates. Furthermore, Study 2 conceptually replicated the findings of Study 1 and extended them to a different large and diverse sample. Finally, the results suggest that simply perceiving a lack of ideological fit may be enough to increase the desire to migrate to a new community.

The findings in Study 2 are consistent with the ideological migration hypothesis and with the data presented in Study 1, but the causal conclusions remain limited by the fact that the data are correlational. Thus, in Study 3, we experimentally manipulated ideological fit to test the causal effect of fit on desire to migrate.

\section{Study 3: Ideological Fit Influences Migration Desires}

\footnotetext{
${ }^{10}$ We tested the reverse mediation model, which was counter to our hypothesis, to further clarify the relations between the variables. Following the same approach, we conducted a regression showing the significant direct effect of ideological fit on the desire to migrate (unstandardized $B=.42, S E=0.028, t=14.48, p<.001, p r^{2}=.17$ ), another regression showing that the desire to migrate is a significant predictor of sense of belonging (unstandardized $B=-.57, S E=0.026, t=-21.71, p<.001, p r^{2}=.32$ ). A final regression with both ideological fit and desire to migrate predicting sense of belonging showed that both ideological fit (unstandardized $B=.29, S E=.03, t=11.43$, $p<.001, p r^{2}=.12$ ) and desire to migrate (unstandardized $B=-.49, S E=.03, t=-19.40, p<.001, p r^{2}=.27$ ) remained significant independent predictors of sense of belonging. The Sobel's test was significant, $z=10.49, p<$ .001 , but the persisting prediction of both ideological fit and desire to migrate shows that desire to migrate cannot completely account for the relationship between ideological fit and feeling of belonging. As such the reverse mediation pattern is a less parsimonious account of the relations among variables than our preferred account.
} 
In Study 3, we experimentally manipulated the perceived ideological worldview of one's community and then assessed their desire to migrate. Students read about the changing ideological worldview of their university and then answered questions about their sense of belonging at the university and desire to transfer. For some, the changes increased community fit with their ideology; for others, the changes decreased community fit with their ideology. This permits a strong test of the ideological migration hypothesis, as students have already chosen to attend a university and transferring is an indicator of the desire to move out of the current living environment for college students. Once people have chosen one course of action, such as which university to attend, they will view that decision more favorably and be less willing to relinquish the identity that came with that decision, such as being a student at that university (i.e., cognitive dissonance and the endowment effect; Brehm, 1956; Kahneman, Knetsch, \& Thaler, 1990). Therefore, desire to transfer must compete with the psychological processes that foster attachment and commitment to one's community.

\section{Method}

\section{Participants}

Participants consisted of 102 undergraduate students (62 female, 40 male) at the University of Virginia, ranging in age from 18 to $30(M=19.37, S D=1.54)$, who self-identified as liberal $(n=63)$ or conservative $(n=39)$ on a department-wide demographic pre-test. Our sample size was designated to be as many as we could collect from the department participant pool in the spring semester of 2012. Participants received partial course credit in exchange for their participation in this study.

\section{Materials and Procedure}


Participants came into the laboratory and were informed that they would be reading a

news article and then providing their reactions. Participants read one of three versions of a news

article, titled "The Changing Political Landscape of Colleges," that contained four paragraphs.

The first three paragraphs were identical across conditions.

Talking heads have been discussing how the political landscape in the United States has been changing in recent decades where liberals and conservatives have been moving into communities that are increasingly liberal and conservative, respectively. Bill Bishop, author of The Big Sort, has compiled data demonstrating how Americans have been sorting themselves into homogeneous communities "not just at the regional level, or the red-state/blue-state level, but at the micro-level of city and neighborhood, too."

Robert Putnam, author of Bowling Alone: The Collapse and Revival of American Community, suggests that this tendency may actually have positive health consequences, as people are finding themselves in communities where people share their values and where they do not need to fear being criticized for the beliefs about contentious political issues like global warming, intelligent design, and same-sex marriage.

Researchers from US News and World Report, who release an annual report on the best colleges and provide advice to high school students on how to select the best college for them, found that the political landscapes of universities have been changing, too. While universities tend to be more liberal than conservative, these researchers found an emerging polarization at many schools. Students are becoming more liberal and more conservative, with fewer students identifying as "moderate" or "neutral."

The fourth paragraph contained the critical manipulation, providing information on which

colleges were becoming more liberal and which were becoming more conservative. Specifically,

the article paragraph stated:

The upcoming 2012 edition of the US News and World Report on colleges and universities ranks Liberty University in Virginia as the most conservative and Macalester College in Minnesota as the most liberal. They noted that among large universities, the University of Virginia [Penn State University / University of Kansas] appears to be increasingly attractive to conservatives and Penn State University [University of Virginia] appears to be increasingly attractive to liberals. At the current rate of high school and university transfer applications, the University of Virginia will be one of the few universities where the majority of students are conservative and the Penn State University will have the highest percentage of liberal students relative to the number of conservative students.

In the control condition, the University of Virginia was not mentioned and the article claimed

that the University of Kansas and Penn State University were the most rapidly changing institutions. 
After participants read the article, they completed a brief questionnaire. The first question asked, "How satisfied are you at the University of Virginia?" and response options ranged from 1 (Very dissatisfied) to 6 (Very satisfied). Seven questions assessed participants sense of belonging ("I feel like I belong at my current university," "I am comfortable at the University of Virginia," "I am glad I chose to attend the University of Virginia," "I have a lot of school spirit," "I feel at home at my school," The people at my university accept me," and "I feel welcomed at the University of Virginia.") on a 6-point Likert-type item ranging from 1 (Definitely Not) to 6 (Definitely), Cronbach's $\alpha=.85$. Then, participants completed two questions assessing the desire to transfer from the university ("I have considered / would consider transferring from the University of Virginia," and "I would like to be a student at a different university," $r[96]=.56$ ). Finally, participants were asked to estimate the percentage of students at the University of Virginia who shared their political values ("What percent of students at UVa do you believe share your political beliefs?"). As in Study 2, this estimate served as the index of perceived ideological fit. The correlations between the measured variables are documented in Table 4 .

\section{Results}

\section{Manipulation Check}

We examined whether the manipulation altered the perceived ideological fit using a 2 (Liberals vs. Conservatives) x 3 (UVa Becoming More Liberal vs. UVa Becoming More Conservative vs. Control) between subjects ANOVA. Liberals perceived that a higher percentage of people shared their values $(M=49.13, S D=16.57)$ than did conservatives $(M=41.11, S D=$ 17.04), regardless of manipulation condition, $F(1,94)=6.59, p=.012, \eta_{\mathrm{p}}^{2}=.07$. The manipulation had no significant main effect on perceived percentage of people sharing participants' values, $F(2,94)=0.12, p=.88, \eta_{\mathrm{p}}{ }^{2}=.003$. There was, however, the predicted 
significant interaction between political orientation and the ideological fit manipulation, $F(2,94)$ $=14.95, p=2.0 \times 10^{-6}, \eta_{\mathrm{p}}{ }^{2}=.24$. Simple main effects analyses showed that when liberals read that UVa is becoming more liberal, they perceived that a greater percentage of students at UVa shared their values $(M=60.43, S D=12.27)$ than when conservatives read that $\mathrm{UVa}$ is becoming more liberal $(M=29.64, S D=17.15), F(1,94)=33.69, p=1.0 \times 10^{-6}, \eta_{\mathrm{p}}^{2}=.26$. When liberals read that UVa is becoming more conservative, they perceived a marginally lower percentage of students at UVa who shared their values $(M=41.96, S D=12.14)$ than when conservatives read that UVa is becoming more conservative $(M=50.92, S D=15.67), F(1,94)=3.02, p=.08, \eta_{\mathrm{p}}{ }^{2}=$ .03. Liberals $(M=46.68, S D=19.71)$ and conservatives $(M=44.09, S D=6.25)$ did not significantly differ in the control condition, $F(1,94)=0.21, p=.65, \eta_{\mathrm{p}}^{2}=.002$.

Because we were interested in testing the effect of ideological fit vs. ideological misfit on the desire to transfer, we combined the personal ideology and experimental condition variables to create the independent variable with three levels: (a) ideological fit condition: liberal participants in the UVa becoming more liberal condition and conservative participants in the UVa becoming more conservative condition; (b) ideological misfit condition: liberal participants in the UVa becoming more conservative condition and conservative participants in the UVa becoming more liberal condition; and (c) control condition. This independent variable did not interact with political orientation, $F(2,94)=0.84, p=.44, \eta_{\mathrm{p}}^{2}=.01$ showing that we did not lose an important explanatory factor by simplifying the conditions. It did, however, demonstrate the predicted effect on perceived ideological fit, $F(1,94)=14.26, p=4.0 \times 10^{-6}, \eta_{\mathrm{p}}{ }^{2}=.23$. Participants in the ideological fit condition reported greater perceived ideological fit $(M=56.24, S D=14.50)$ than control participants $(M=45.73, S D=16.05)$, who perceived greater ideological fit than participants in the ideological misfit condition $(M=37.30, S D=15.39), p s<.013$. Thus, the 
experimental manipulation of perceived ideological fit was effective in changing the perception that the university community shared their ideological values, and this manipulation operated similarly for both liberal and conservative participants.

\section{Decreasing ideological fit increases the desire to transfer}

We tested whether decreased ideological fit would increase desires to transfer from UVa. In a one-way ANOVA, decreasing ideological fit increased desire to transfer, $F(2,99)=8.00, p$ $=.001, \eta_{\mathrm{p}}{ }^{2}=.14$. Tukey's HSD test revealed that participants in the ideological misfit condition expressed significantly elevated desires to migrate $(M=2.86, S D=1.71)$ relative to the participants in the ideological fit $(M=1.72, S D=0.85 ; p=.001$; Cohen's $d=0.85)$ and control $(M=1.85, S D=1.18 ; p=.002 ;$ Cohen's $d=0.68)$ conditions. The ideological fit and control conditions were both within one standard deviation of the bottom of the scale and did not significantly differ from one another, $p=.59$ (Cohen's $d=0.12$ ).

\section{Ideological fit increases sense of belonging}

Next, we examined whether the ideological misfit would lower participants' sense of belonging at the university. In a one-way ANOVA, ideological fit predicted sense of belonging, $F(2,94)=8.92, p=2.7 \times 10^{-5}, \eta_{\mathrm{p}}^{2}=.15$. Tukey's HSD test revealed that participants in the ideological misfit condition reported a reduced sense of belonging $(M=4.16, S D=1.35)$ relative to the ideological fit $(M=5.01, S D=0.83)$ and control conditions $(M=5.09, S D=.72$; all $p$ s < .001). Sense of belonging did not differ between the ideological fit and control conditions, $p=$ .76.

\section{Sense of belonging mediates the effect of ideological fit on the desire to transfer}

To test the prediction that sense of belonging mediates the relationship between ideological fit and the desire to migrate, like Study 2, we conducted mediation analyses. 
First, we contrast-coded the ideological fit manipulation (ideological misfit $=-1$, control $=0$, ideological fit $=1$ ) and confirmed that fit predicted desire to migrate, unstandardized $B=$ $.58, S E=0.16, t=3.67, p=4.0 \times 10^{-5}$. Next, we confirmed that the ideological fit manipulation predicted sense of belonging, unstandardized $B=-.43, S E=0.12, t=-3.49, p=.001$. Then, we confirmed that sense of belonging predicted the desire to transfer, unstandardized $B=-.96, S E=$ $0.08, t=-11.58, p=1.0 \times 10^{-7}$. Finally, a regression including both the ideological fit manipulation and sense of belonging showed that the ideological fit manipulation no longer predicted the desire to migrate (unstandardized $B=.17, S E=.12, t=1.54, p=.13, p r=.15$ ), while the hypothesized mediator, sense of belonging, continued to predict the desire to transfer (unstandardized $B=-.92, S E=.09, t=-10.50, p<1.0 \times 10^{-7}, p r=-.68$ ). Sobel's significance test for mediation supported this hypothesis, Sobel's $z=3.43, p=2.9 \times 10^{-5}$.

Next, we used self-reported perceived ideological fit as the independent variable, instead of the manipulated variable. In other words, we tested whether the link between perceived (selfreported) ideological fit and desire to transfer would be mediated by sense of belonging. As predicted, we found that perceived ideological fit predicted the desire to transfer, unstandardized $B=-.031, S E=0.008, t=-3.97, p=1.3 \times 10^{-5}$. Next, we confirmed that ideological fit predicted sense of belonging, unstandardized $B=.028, S E=.006, t=4.64, p=1.1 \times 10^{-5}$. Finally, a regression including perceived ideological fit and sense of belonging predicting the desire to transfer showed that the perceived ideological fit was no longer a significant predictor of the desire to transfer (unstandardized $B=-.005, S E=.006, t=-0.85, p=.39, p r=-.06$ ), while the hypothesized mediator, sense of belonging, continued to predict the desire to migrate 
(unstandardized $B=-.93, S E=.09, t=-10.00, p<1.0 \times 10^{-6}, p r=-.66$ ). Sobel's significance test for mediation supported this hypothesis, Sobel's $z=-4.33, p=1.4 \times 10^{-5}$. See Figure $4^{11}$.

\section{Discussion}

Study 3 conceptually replicated Studies 1 and 2, and extended them by experimentally demonstrating that reduced ideological fit increases migration desires. Study 3 also replicated the mediational model from Study 2, providing further support for the argument that migration is motivated by the need to belong. Study 3 used ideology as a measured individual difference variable and only manipulated ideological fit rather than trying to manipulate both. Therefore, in Study 4, we experimentally manipulated both ideology and perceived community ideology as orthogonal factors, thus exerting full experimental control over these variables and the fit between them.

\section{Study 4: Manipulating Perceived Personal and Community Ideology}

In Study 4, we utilize a full experimental approach. As ideology is a relatively stable characteristic, it is difficult to manipulate among ideologues (see Alford, Funk, \& Hibbing, 2005; see also Jost, 2008). Thus, we developed a similar design as Study 3 and then recruited people who may not yet have a clear ideological identity_people describing themselves as "neutral," or "moderate" - and gave them bogus feedback to lead them to believe that they are more liberal or conservative than they previously thought. This approach will provide an even stronger test for

\footnotetext{
${ }^{11}$ We tested the reverse mediation model, which was counter to our hypothesis, to further clarify the relations between the variables. Following the same approach, we conducted a regression showing the significant direct effect of ideological fit on sense of belonging (unstandardized $B=-.44, S E=.12, t=-3.49, p=.001, p r^{2}=.11$ ), another regression showing that the desire to migrate is a significant predictor of sense of belonging (unstandardized $B=$ $.59, S E=0.05, t=-11.58, p<1.0 \times 10^{-6}, p^{2}=.56$ ). A final regression including ideological fit and desire to migrate showed that ideological fit no longer predicted sense of belonging (unstandardized $B=-.10, S E=.09, t=-1.12, p=$ $. .26, p r^{2}=.01$ ) but desire to migrate did (unstandardized $B=-.57, S E=.06, t=-10.50, p<1.0 \times 10^{-6}, p r^{2}=.51$ ). Sobel's test for mediation was significant, Sobel's $z=-3.46, p=1.0 \times 10^{-4}$. Given the strong correlation between sense of belonging and desire to migrate, this is not surprising. It is important to note, though, that the hypothesized model demonstrates a greater reduction in the relationship between ideological fit and the outcome variable. Further, the reverse mediation model fits the data less well than the hypothesized model by $21 \%$, Sobel's $z$ for the hypothesized model $=-4.34$ compared to Sobel's $z$ for the reverse model $=-3.46$.
} 
the ideological migration hypothesis, and demonstrate that people garner a sense of belonging from being around people with similar ideological values.

\section{Method}

\section{Participants}

Participants consisted of 84 undergraduate students (50 female, 34 male) at the University of Virginia, ranging in age from 18 to $23(M=19.01, S D=1.28)$, who self-identified as "moderate/neutral" on a demographic pre-test. Our sample size was designated to be 20 participants per cell; data collection was terminated the day on which we met this criterion. Participants received partial course credit in exchange for their participation in this study.

\section{Materials and Procedure}

Participants entered the laboratory and were informed that they would be participating in two short studies. The first study was described as a study on a new measure of political attitudes that could help voters make sense of a complicated political world. In this first "study," participants were given one of two 7-item questionnaires that presented an argument advocating an extreme conservative or extreme liberal position (e.g., "Women should never have the right to have an abortion." vs. "Women should always have the right to have an abortion."). Participants indicated that they agreed or disagreed with each of the 7 statements. Due to the extreme nature of the items, they were nearly unanimously rejected. Upon completing the questionnaire, they scored themselves by counting the number of statements with which they agreed. On the selfscoring key, they read that disagreeing with the majority of the items means that they are: more liberal (if the questionnaire they received consisted of the extreme conservative positions) or more conservative (if the questionnaire they received consisted of the extreme liberal positions). 
After completing this "first study," participants were given one of two of the news articles from Study 3, which stated that UVa was becoming more liberal or more conservative. After this article, they completed the same measures as in Study 3, with an additional question assessing the effectiveness of the ideology manipulation. This question asked participants to place themselves on a 6 -point ideological scale $(1=$ very liberal to $6=$ very conservative $)$. Upon completion, participants were fully debriefed and thanked for their participation.

The correlations between the measured variables are documented in Table 4 .

\section{Results}

\section{Manipulation Check}

The manipulation of participant ideology had a significant effect on their self-reported ideology, $F(1,81)=28.13, p<1.0 \times 10^{-7}, \mu_{\mathrm{p}}^{2}=.26$. Specifically, participants given the bogus feedback to think that they were more liberal, self-identified as more liberal $(M=2.42, S D=$ 0.72) than participants given the bogus feedback to think they were more conservative $(M=3.38$, $S D=0.92)$

\section{Ideological Misfit Increases Migration Desire and Decreases Sense of Belonging}

As in Study 3, we created a single composite variable of "fit" for participants given feedback to think they were more liberal and who read that UVa was becoming more liberal or participants given feedback to think they were more conservative and who read that UVa was becoming more conservative, and "misfit" for participants given feedback that was different from the changing ideology at UVa. Misfit participants expressed a significantly greater desire to migrate $(M=2.02, S D=0.83)$ than did fit participants $(M=1.63, S D=.82), F(1,82)=4.70, p=$ $.03, \mu_{\mathrm{p}}^{2}=.05$. Misfit participants also reported feeling that they belonged less $(M=4.89, S D=$ $0.68)$ than fit participants $(M=5.23, S D=0.77), F(1,82)=4.56, p=.04, \mu_{\mathrm{p}}^{2}=.05$. 


\section{Sense of belonging mediates the effect of ideological fit on desire to migrate}

To test the prediction that sense of belonging mediates the relationship between ideological fit and the desire to migrate, like Studies 2 and 3, we conducted mediation analyses.

First, we dummy-coded the ideological fit (ideological misfit $=0$, ideological fit $=1$ ) and confirmed that fit predicted desire to transfer, unstandardized $B=-.39, S E=0.18, t=-2.17, p=$ .03. Next, we confirmed that ideological fit predicted sense of belonging, unstandardized $B=-$ $.34, S E=0.11, t=-2.14, p=.03$. Then, we confirmed that sense of belonging predicted the desire to migrate, unstandardized $B=-.60, S E=0.10, t=-5.69, p<1.0 \times 10^{-7}$. Finally, a regression including both ideological fit and sense of belonging showed that the ideological fit no longer significantly predicted the desire to migrate (unstandardized $B=.20, S E=.16, t=$ $1.19, p=.23, p r=-.13)$, while the hypothesized mediator, sense of belonging, continued to predict the desire to migrate (unstandardized $B=-.57, S E=.11, t=-5.27, p=1.0 \times 10^{-6}, p r=-$ $.50)$. Sobel's significance test for mediation supported this hypothesis, Sobel's $z=-2.01, p=.04$. See Figure 5.

\section{Discussion}

Study 4 replicates and extends Study 3, showing that the perceived fit between the participant's ideology and the community's ideology decreases the desire to migrate and increases sense of belonging, with both variables experimentally manipulated. As in Studies 2 and 3, sense of belonging mediated the relationship between ideological fit and the desire to migrate.

\section{General Discussion}

We theorized that people seek communities with ideologies that fit their own. In Study 1, we found correlational evidence in a large national sample suggesting that people who lived in 
communities where their ideological values were misfit were more likely to have migrated.

Moreover, when participants migrated, they did so in a fashion that reduced the degree of misfit between their personal ideological worldview and their community's ideological worldview. In Study 2, we found correlational evidence in a different national sample showing that participants can infer the ideological worldview of their community, determine the degree to which their worldviews fit their community's ideological worldview, perceive a sense of belonging from this perceived fit, and desire to migrate from communities with values that do not fit their own personal worldview. In Study 3, we experimentally manipulated perceptions of ideological fit and found that perceiving a lack of ideological fit decreased sense of belonging in one's community and increased the desire to migrate to a different community. In Study 4, we experimentally manipulated participants' perception of their own ideology and their perception of their community's ideology and found that being informed that one's ideology is incongruent with their community's ideology increased the desire to migrate and decreased sense of belonging. In Studies 1 and 2, we found that a misfit between the person's and their community's moral values predicts retrospective and prospective migration, respectively. In Studies 2, 3, and 4, we found that sense of belonging mediated the relationship between ideological fit and the desire to migrate. Together, these 4 studies utilize different methods and samples to provide converging evidence that a discrepancy between personal and community ideological values increases migration tendencies, and that this relationship is mediated by the sense of belonging.

These findings provide empirical support for the ideological migration hypothesis that people may selectively migrate to communities that fit better with their ideological worldviews. The current research does not differentiate between the community-level extrapolations of the similarity-attraction effect (Byrne, 1971), whereby people are drawn toward similar 
communities, or the repulsion hypothesis (Rosenbaum, 1986), whereby people are repelled away from dissimilar communities. We expect that both processes are influential.

\section{Is Ideological Migration Good?}

This tendency to migrate into increasingly ideologically- and morally-homogeneous communities may have a number of positive consequences. Individuals migrate to homogeneous enclaves to increase their sense of belonging with their communities. Having a strong sense of belonging has many positive psychological consequences such as improved academic performance, reduced mental and physical health problems, and subjective well-being (Haslam, Jetten, Postmes, \& Haslam, 2008; Leary, 2009; Major \& O’Brien, 2005; Motyl \& Oishi, 2013; Sheldon \& Bettencourt, 2010; Walton \& Cohen, 2011). Further, homogeneity on moral values may reduce daily interpersonal conflict with dissimilar others. Indeed, among types of diversity, moral diversity is very unpopular (Haidt, Rosenberg, \& Hom, 2003). Without fear of reprisal for expressing one's values, one may be able to more easily form strong interpersonal bonds and accumulate social capital (see Coleman, 1988; Putnam, 2000).

With better social bonds and increased social capital, people may more easily flourish. When people feel like their values matches their environment, they experience greater subjective well-being and increased self-esteem (Fulmer et al., 2010). In turn, heightened subjective wellbeing promotes longevity, reduces bad cholesterol and blood pressure, and expedites recovery from negative emotional experiences (Danner, Snowdon, \& Friesen, 2001; Fredrickson, 2000; Fredrickson \& Joiner, 2002; Fredrickson \& Levenson, 1998; see Lyubomirsky, King, \& Diener, 2005 for a review). People may even be reducing the suicide rate by migrating into these enclaves where they are buffered from moral despair and "social disintegration" (Classen \& Dunn, 2010; Durkheim, 1897). 
Within-group functioning may also be enhanced by homogeneous moral communities. For example, increasing a sense of belonging among marginalized groups can increase academic achievement (Schmitt, Oswald, Friede, Imus, \& Merritt, 2008; Walton \& Cohen, 2007). Similarly, work teams composed of employees with similar values outperformed works teams composed of employees with diverse values (Baugh \& Graen, 1997; Ely \& Thomas, 2001; Hartel \& Fujimoto, 1999; Guillaume, Brodbeck, \& Riketta, 2012; van Knippenberg \& Schippers, 2007). And, employees prefer working in teams comprised of individuals with similar values, more so than teams comprised of individuals with similar demographic characteristics (Hobman, Bordia, \& Gallois, 2003; Jackson et al., 1991; Jehn, Chadwick, \& Thatcher, 1997; Pelled, 1996). Thus, the consequences of ideological migration into increasingly homogeneous enclaves may be positive for the individuals and community itself.

\section{Or, Is Ideological Migration Bad?}

At the same time, segregating people into ideological or moral communities could also have negative consequences. Ideological segregation necessarily leads to reduced contact between members of the segregated groups. There is a long history of research demonstrating that reduced intergroup contact lays the foundation for future conflict and prejudice (Allport, 1954; Shaw \& Zarate, 2007). When people do not have contact with members of an outgroup, they are more likely to view members of that outgroup as less than human (see Bandura, 1999; Goldenberg, Heflick, Vaes, Motyl, \& Greenberg, 2009; McKeown, Cairns, Stringer, \& Rae, 2012). Viewing outgroups as subhuman is a critical mechanism that permits people to perpetrate violent acts, such as supporting extreme military actions attacking the homelands of those outgroups (McAlister, Bandura, \& Owen, 2006; Motyl \& Pyszczynski, 2010; Pyszczynski, Motyl, \& Abdollahi, 2009). 
Luckily, the culture war in the United States is mostly a rhetorical war and not a literal one. However, like the children in Sherif's (1966) Robber's Cave study, liberals and conservatives living in separate camps often describe each other in derogatory, dehumanizing terms, and question each other's moral integrity (Robinson, Keltner, Ward, \& Ross, 1995). This lack of communication and shared experiences that result from living in the same community may prevent liberals and conservatives from understanding each other (Ditto \& Koleva, 2011) and increase the likelihood of incivility (Jost, Ledgerwood, \& Hardin, 2007; Motyl et al., 2011). The gradual increase in moral segregation due to migration may be forming "complicit surrounds" that polarize group attitudes and create an ethos tolerant of hostile, uncivil behavior against outgroup members (Motyl \& Pyszczynski, 2010; Pyszczynski, Motyl, \& Abdollahi, 2009; Reicher, Haslam, \& Rath, 2008; Richardson, 2006). Thus, the recent trend of growing demonization and hostility (Haidt, 2012; Hill, 2005; Sapiro, 2006) may be due to the simple fact that migration and segregation reduces communication and interdependence among liberals and conservatives (Mutz, 2006). In short, ideological migration is a national unraveling of intergroup contact. Ideological migration might increase "bonding" with similar others, but decrease "bridging" with dissimilar others (Putnam, 2007).

\section{Limitations}

Our samples were not representative and tended to be disproportionately liberal. In Study 1, conservatives were slightly more likely to show this ideological migration effect than were liberals (the effect sizes differed by a mere 1\%). In Study 2, however, liberals were slightly more likely to show this ideological migration effect than were conservatives (again the effect sizes differ by just under 1\%). Given the large samples, virtually all inferential statistics were statistically significant. The explanation and practical significance of these slight differences that 
vary across samples and studies is not clear from the present research. Furthermore, in Study 3, liberals and conservatives did not differ in their desires to migrate across ideological fit conditions. Thus, it is unclear whether the ideological migration effect differs for people across the ideological spectrum.

Studies 1 and 2 were conducted on very large and diverse samples collected on the internet, but they were not representative of any definable population (Nosek, Smyth, et al., 2007). While not representative samples, they are more diverse than the convenience samples of college students often used in psychological research (Gosling, Sandy, John, \& Potter, 2012; Gosling, Vazire, Srivastava, \& John, 2004). Yet, we do not claim that the estimates provide parameter estimates of migration patterns for liberals and conservatives. They do, however, show that the effects are widespread and occur for a diverse sample across politics, regions of the U.S., and demographic characteristics.

Further, the effect sizes found were not large, and in other research (Iyer, 2012; see also Motyl, Iyer, Trawalter \& Haidt, 2013), the desire to live near people of the same ideological group has been found to be relevant, though perhaps less important than having good job opportunities, safety, and clean air, when considering a place to live. Yet, the present research provides strong correlational and experimental evidence that it does matter, as well as a psychological explanation for why it occurs. One limitation of the current research is that the samples are not representative of the U.S. or world populations. The studies were conducted online or at a major university. These samples may be of higher socio-economic status and therefore more likely to move to satisfy psychological, as opposed to physical needs, than more representative samples. Previous research has indicated that as people become wealthier (Inglehart, 2008), they value the satisfaction of psychological needs more highly, and in Study 2, 
the predicted interaction was not found among less wealthy participants. It is possible that ideological migration is a trend that occurs once physical needs are met, a theory which would be consistent the recent rise of ideological clustering and a segregated political geography (Bishop, 2009). Future research will hopefully explore the moderators and boundary conditions of ideological migration.

\section{Future Directions}

We observed that people's perception of the ideology of their community was correlated with the actual ideological values of the community - as indexed by presidential voting patterns. How participants perceive the community's ideology is unknown. Given the low levels of political knowledge among voters in the United States (Campbell et al., 1964; Delli-Carpini \& Keeter, 1996), it is curious that people are able to migrate into communities that are increasingly congruent with their personal moral and political values. It is possible that people may not have much political knowledge as it is defined by political scientists - e.g., knowing the composition of the Supreme Court or the number of members of the House of Representatives (Gilens, 2001; Kuklinski \& Quirk, 2001) - but that they do have a good deal of political knowledge that is actually useful to them (Carney et al., 2008; Lupia, 2006; Prior \& Lupia, 2008). For example, people may be quite reliable in reporting the likely values of people who drive hybrid cars and drink lattes versus people that go hunting and watch NASCAR. Identifying moral and political values of individuals or communities may draw on social indicators like these rather than tracking voting patterns. People can determine personality characteristics and political worldviews by looking at bedrooms, dorm rooms, and office spaces (Gosling et al., 2006). They might similarly use community cues, such as the presence of certain types of cars, churches, 
restaurants, and stores, to make judgments about the ideology, morality, and personality of the community (Bishop \& Cushing, 2008; Iyer, 2012; Motyl, Iyer, Trawalter, \& Haidt, 2012).

These differences in the ideological worldviews of individuals and their communities may speak to a larger phenomenon. Today, ideology implies the core values that span most of a person's moral worldview and that there are important differences between people who adhere to one worldview or another (Graham et al., 2013; Jost et al., 2003; Jost, 2008). Much in the same way that race is discussed, there are cultural and lifestyle differences between liberals and conservatives. Hunter (1991) argues that conservatives prefer an "orthodox" lifestyle that is rooted in respect for authority and a tendency toward tradition. He argues that liberals, on the other hand, prefer a "progressive" lifestyle that tends more toward challenging authority in pursuit of promoting human flourishing for all citizens equally. Hetherington and Weiler (2009) examined this hypothesis by looking at how traditional, non-political behaviors in one's life space predict their political behaviors in the broader social context. They found a very strong correlation between parents' belief in spanking their children as a necessary form of discipline and their support for President George W. Bush in the 2004 presidential election (Pearson's $r$ s ranged from .79 to .83 across two analyses). Numerous other scholars demonstrate a considerable correlation between moral and political identities (e.g., Abramowitz, 2012; Graham et al., 2009; Haidt \& Graham, 2007; Koleva et al., 2011). Thus, ideological migration might be considered moral migration; the current work, though, is limited to political ideology and does not test the possibility that ideology is indeed a proxy indicator of morality. We hope that future research explores this question.

\section{Conclusion}


Arthur Miller (2004) once asked "How can the polls be neck-and-neck when I don't know a single [George W.] Bush supporter?" The present research suggests a contributing factor: liberals and conservatives may be migrating to enclaves where they are less likely to know one another. Perceived ideological fit with a community predicts desire to move away from incongruent communities and into congruent communities. Furthermore, ideological migration appears to operate to satisfy the psychological need to belong. As a consequence, the desire to belong may be responsible for increasing ideological homogeneity and segregation. While this homogenization of communities may promote greater personal well-being by satisfying our need to belong, it may also foster increased partisan hostility by minimizing our contact with people who hold discrepant moral and political beliefs. 


\section{References}

Abramowitz, A. I. (2012). The polarized public? Why American government is so dysfunctional. Pearson Education: Boston, MA.

Allport, G. W. (1954). The nature of prejudice. New York, NY: Addison-Wesley.

Anderson, M. R. (2009). Beyond membership: A sense of community and political behavior. Political Behavior, 31, 603-627.

Avlon, J. (2010). Wingnuts: How the lunatic fringe is hijacking America. New York, NY: Beast Books.

Bandura, A. (1999). Moral disengagement in the perpetration of inhumanities. Personality and Social Psychology Review, 3, 193-209.

Baron, R. M., \& Kenny, D. A. (1986). The moderator-mediator variable distinction in social psychological research: Conceptual, strategic, and statistical considerations. Journal of Personality and Social Psychology, 51, 1173-1182.

Baugh, S. G., \& Graen, G. B. (1997). Effects of team gender and racial composition on perceptions of team performance in cross-functional teams. Group \& Organization Management, 22, 366-383.

Baumeister, R. F., \& Leary, M. R. (1995). The need to belong: Desire for interpersonal attachments as a fundamental human motivation. Psychological Bulletin, 117, 497-529.

Bishop, B. (2008). The big sort: Why the clustering of like-minded America is tearing us apart. Boston, MA: Houghton-Mifflin Harcourt.

Bishop, B., \& Cushing, R. (2008). The Big Sort: Migration, Community, and Politics in the United States of 'Those People'. In R. A. Teixeira (Ed.), Red, Blue \& Purple America: 
The Future of Election Demographics. (p. 50-78). Washington, DC: Brookings Institution.

Brehm, J. (1956). Post-decision changes in desirability of alternatives. Journal of Abnormal and Social Psychology, 52, 384-389.

Burr, T. (2013). Gridlock - The new normal in Washington. The Salt Lake Tribune. Retrieved January 5, 2013 from http://www.sltrib.com/sltrib/politics/55572190-90/says-congresscompromise-lee.html.csp

Byrne, D. E. (1971). The attraction paradigm. Academic Press: New York, NY.

Byrne, D., Clore, G. L., \& Smeaton, G. (1986). The attraction hypothesis: Do similar attitudes affect anything? Journal of Personality and Social Psychology, 51, 1167-1170. doi: 10.1037/0022-3514.51.6.1167

Campbell, A., Converse, P., Miller, W. E., \& Stokes, D. E. (1960). The American voter. New York: John Wiley \& Sons, Inc.

Carney, D. R., Jost, J. T., Gosling, S. D., \& Potter, J. (2008). The secret lives of liberals and conservatives: Personality profiles, interaction styles, and the things they leave behind. Political Psychology, 29, 807-840.

Chilcote, R. H. (2011). The Obama initiative. LASA Forum, XLII, 26-27.

Chinni, D., \& Gimpel, J. (2010). Our patchwork nation: The surprising truth about the "real" America. The 12 community types that make up our nation. New York, NY: Gotham Books.

Cialdini, R. B., \& Goldstein, N. J. (2004). Social influence: Compliance and conformity. Annual Review of Psychology, 55, 591-621. 
Classen, T. J., \& Dunn, R. A. (2010). The politics of hope and despair: The effect of presidential election outcomes on suicide rates. Social Science Quarterly, 91, 593-612. DOI: $10.1111 / \mathrm{j} .1540-6237.2010 .00709 . \mathrm{x}$

Converse, P. E. (1964). The nature of belief systems in the mass public. In David Apter, (ed.) Ideology and Discontent. New York: Free Press.

Craik, K. H. (2000). The lived day of an individual: A person-environment perspective. In W. W. Bruce, K. H. Craik, \& R. H. Price (Eds.), Person-environment psychology: New directions and perspectives ( $2^{\text {nd }}$ ed., pp. 233-266). Mahwah, NJ: Lawrence Erlbaum Associates Publishers.

Carpini, M. X. D., \& Keeter, S. (1993). Measuring political knowledge: Putting first things first. American Journal of Political Science, 1179-1206.

Danner, D. D., Snowdon, D. A., \& Friesen, W. V. (2001). Positive emotions in early life and longevity: findings from the nun study. Journal of Personality and Social Psychology, 80, 804-813.

Deutscher, M. (1948). The psychological effects of enforced segregation: A survey of social science opinion. Journal of Psychology, 26, 259.

Ditto, P. H., \& Koleva, S. P. (2011). Moral empathy gaps and the American culture war. Emotion Review, 3, 331-332. doi: 10.1177/1754073911402393

Dixon, J., \& Durrheim, K. (2003). Contact and the ecology of racial division: Some varieties of informal segregation. British Journal of Social Psychology, 42, 1-23.

Durkheim, E. (1897). Suicide: A study in sociology. The Free Press: Glencoe, Illinois. 
Ely, R. J., \& Thomas, D. A. (2001). Cultural diversity at work: The effects of diversity perspectives on work group processes and outcomes. Administration Science Quarterly, 46, 229-273.

Festinger, L. (1963). Social pressures in informal groups: A study of human factors in housing. Stanford University Press: Berkeley, CA.

Florida, R. (2004). Cities and the creative class. Routledge: New York, NY.

Florida, R. (2008). Who's your city? How the creative economy is making where to live the most important decision of your life. Basic Books: New York, NY.

Fredrickson, B. L. (1998). What good are positive emotions? Review of General Psychology, 2, 300.

Fredrickson, B. L., \& Joiner, T. (2002). Positive emotions trigger upward spirals toward emotional well-being. Psychological science, 13, 172-175.

Fredrickson, B. L., \& Levenson, R. W. (1998). Positive emotions speed recovery from the cardiovascular sequelae of negative emotions. Cognition \& Emotion, 12, 191-220.

Fulmer, C. A., Gelfand, M. J., Kruglanski, A. W., Kim-Prieto, C., Diener, E., Pierro, A., \& Higgins, E. T. (2010). On "Feeling Right" in Cultural Contexts How Person-Culture Match Affects Self-Esteem and Subjective Well-Being. Psychological Science, 21, 15631569.

Furnham, A. (1982). Psychoticism, social desirability and situation selection. Personality and Individual Differences, 3, 43-51.

Gilens, M. (2001). Political ignorance and collective policy preferences. American Political Science Review, 95, 379-396. 
Gimpel, J., \& Chinni, D. (2010). Our patchwork nation: The surprising truth about the "real" America. New York, NY: Penguin Books.

Goldenberg, J.L., Heflick, N.A., Vaes, J., Motyl, M., \& Greenberg, J. (2009). Of mice and men, and objectified women: Terror management as an explanatory framework for infrahumanization effects. Group Processes and Intergroup Relations, 12, 1-14.

Goldstein, J. S. (2011). Winning the War on War: The Decline of Armed Conflict Worldwide. Dutton Adult.

Gosling, S. D., Sandy, C. J., John, O. P., \& Potter, J. (2010). Wired but not WEIRD: The promise of the Internet in reaching more diverse samples. Behavioral and Brain Sciences, $33,94-95$.

Gosling, S. D., Vazire, S., Srivastava, S., \& John, O. P. (2004). Should we trust web-based studies? A comparative analysis of six preconceptions about internet questionnaires. American Psychologist, 59, 93-104.

Graham, Jesse, Haidt, Jonathan, Koleva, Sena, Motyl, Matt, Iyer, Ravi, Wojcik, Sean P. and Ditto, Peter H., Moral Foundations Theory: The Pragmatic Validity of Moral Pluralism (November 28, 2012). Advances in Experimental Social Psychology, Forthcoming. Available at SSRN: http://ssrn.com/abstract=2184440

Graham, J., Nosek, B. A., Haidt, J., Iyer, R., Koleva, S., \& Ditto, P. H. (2011). Mapping the moral domain. Journal of Personality and Social Psychology, 101, 366-385.

Greenblatt, A. (2012). When it comes to Politics, States are Barely United. NPR. Retrieved 1/7/13 from http://www.npr.org/blogs/itsallpolitics/2012/12/26/168068305/when-itcomes-to-politics-states-are-barely-united. 
Greenwood, M. J. (1985). Human migration: Theory, models, and empirical studies. Journal of Regional Science, 25, 521-544.

Guillaume, Y. R. F., Brodbeck, F. C., \& Riketta, M. (2012). Surface- and deep-level dissimilarity effects on social integration and individual effectiveness related outcomes in work groups: A meta-analytic integration. Journal of Occupational and Organizational Psychology, 85, 80-115.

Haidt, J., \& Graham, J. (2007). When morality opposes justice: Emotions and intuitions related to ingroups, hierarchy, and purity. Social Justice Research, 20, 98-116.

Haidt, J., Rosenberg, E., \& Hom, H. (2003). Differentiating diversities: Moral diversity is not like other kinds. Journal of Applied Social Psychology, 33, 1-36.

Hartel, C. E. J., \& Fujimoto, Y. (1999). Explaining why diversity sometimes has positive effects in organizations and sometimes has negative effects in organizations: The perceived dissimilarity openness moderator model. Academy of Management Best Papers Proceedings.

Harton, H. C., \& Bullock, M. (2007), Dynamic social impact: A theory of the origins and evolution of culture. Social and Personality Psychology Compass, 1, 521-540. doi: 10.1111/j.1751-9004.2007.00022.x.

Haslam, S. A., Jetten, J., Postmes, T., \& Haslam, C. (2008). Social identity, health and wellbeing: An emerging agenda for applied psychology. Applied Psychology, 58, 1-23.

Hetherington, M. J., \& Weiler, J. D. (2009). Authoritarianism and polarization in American politics. Cambridge University Press.

Hobman, E. V., Bordia, P., \& Gallois, C. (2003). Consequences of feeling dissimilar from others in a work team. Journal of Business and Psychology, 17, 301-325. 
Huckfeldt, R., Mendez, J. M., \& Osborn, T. (2004). Disagreement, ambivalence, and engagement: The political consequences of heterogeneous networks. Political Psychology, 25, 65-95.

Hunter, J. D. (1991). Culture war: The struggle to define America. New York: NY: Basic Books.

Inbar, Y., Pizarro, D., Iyer, R., \& Haidt, J. (2012). Disgust sensitivity, political conservatism, and voting. Social Psychological and Personality Science, 3, 537-544.

Inglehart, R. F. (2008). Changing values among western publics from 1970 to 2006. West European Politics, 31(1-2), 130-146.

Iyer, R., Graham, J., Koleva, S., Ditto, P., \& Haidt, J (2010). Beyond Identity Politics: Moral Psychology and the 2008 Democratic Primary. Analyses of Social Issues and Public Policy, 10, 293-306.

Iyer, R. (2012). Where to live? Liberal, conservative, and libertarian criteria differ. Retrieved January 1, 2013 from http://www.polipsych.com/2012/07/12/where-to-live-liberalsconservatives-libertarians/

Jackson, S. E., Brett, J. F., Sessa, V. I., Cooper, D. M., Julin, J. A., \& Peyronnin, K. (1991). Some differences make a difference: Individual dissimilarity and group heterogeneity as correlates of recruitment, promotions, and turnover. Journal of Applied Psychology, 76, 675-689.

Jehn, K. A., Chadwick, C., \& Thatcher, S. M. B. (1997). To agree or not to agree: The effects of value congruence, individual demographic dissimilarity, and conflict on workgroup outcomes. International Journal of Conflict Management, 8, 287-305.

Jokela, M. (2008). Personality predicts migration within and between US states. Journal of Research in Personality, 43, 79-83. 
Jokela, M., Elovainio, M., Kivimäki, M., \& Keltikangas-Järvinen, L. (2008). Temperament and migration patterns in Finland. Psychological Science, 19, 831-837.

Jost, J. T. (2006). The end of the end of ideology. American Psychologist, 61, 651-670.

Jost, J.T., Glaser, J., Kruglanski, A.W., \& Sulloway, F. (2003a). Political conservatism as motivated social cognition. Psychological Bulletin, 129, 339-375.

Jost, J. T., Ledgerwood, A., \& Hardin, C. D. (2008). Shared reality, system justification, and the relational basis of ideological beliefs. Social and Personality Psychology Compass, 2, 171-186.

Kahneman, D., Knetsch, J., \& Thaler, R. (1990). Experimental tests of the endowment effect and the Coase theorem. Journal of Political Economy, 98, 1325-1348.

Karylowski, J. (1976). Self-esteem, similarity, liking and helping. Personality and Social Psychology Bulletin, 2, 71-74.

Koleva, S. P., Graham, J., Ditto, P., Iyer, R., \& Haidt, J. (2012). Tracing the threads: how five moral concerns (especially Purity) help explain culture war attitudes. Journal of Research in Personality, 46, 184-194.

Kuklinski, J. H., \& Quirk, P. J. (2001). Conceptual foundations of citizen competence. Political Behavior, 23, 285-311.

Latane, B. (1981). The psychology of social impact. American psychologist, 36, 343.

Leary, M. R. (2009). Affiliation, acceptance, and belonging: The pursuit of interpersonal connection. In S. Fiske, D. Gilbert, \& G. Lindzey (Eds.), Handbook of social psychology (4th ed.).

Levendusky, M. (2009). The partisan sort: How liberals became Democrats and conservatives became Republicans. Chicago, IL: University of Chicago Press. 
Lewin, K. (1939). Field theory and experiment in social psychology: Concepts and methods. The American Journal of Sociology, 44, 868-896.

Lupia, A. (2006). How elitism undermines the study of voter competence. Critical Review, 18, 217-232.

Lyubomirsky, S., King, L. A., \& Diener, E. (2005). The benefits of frequent positive affect. Psychological Bulletin, 131, 803-855.

Major, B., \& O’Brien, L. T. (2005). The social psychology of stigma. Annual Review of Psychology, 56, 393-421.

Markus, H. R., \& Kitayama, S. (1991). Culture and the self: Implications for cognition, emotion, and motivation. Psychological Review, 98, 224-253.

Maslow, A. H. (1943). A theory of human motivation. Psychological Review, 50, 370.

McAlister, A. L., Bandura, A., \& Owen, S. V. (2006). Mechanisms of moral disengagement in support of military force: The impact of Sept. 11. Journal of Social and Clinical Psychology, 25, 141-165.

McClurg, S. D. (2006). Political disagreement in context: The conditional effect of neighborhood context, disagreement and political talk on electoral participation. Political Behavior, 28, 349-366.

McKeown, S., Cairns, E., Stringer, M., \& Rae, G. (2012). Micro-ecological behavior and intergroup contact. The Journal of Social Psychology, 152, 340-358.

McPherson, M., Smith-Lovin, L., \& Cook, J. M. (2001). Birds of a feather: Homophily in social networks. Annual Review of Sociology, 27, 415-444.

Moscovici, S., \& Zavalloni, M. (1969). The group as a polarizer of attitudes. Journal of Personality and Social Psychology, 12, 125. 
Motyl, M., Hart, J., Pyszczynski, T., Weise, D., Cox, C., Maxfield, M., \& Siedel, A. (2011). Subtle priming of shared human experiences eliminates threat-induced negativity toward Arabs, immigrants, and peace-making. Journal of Experimental Social Psychology, 47, $1179-1184$.

Motyl, M., Iyer, R., Trawalter, S., \& Haidt, J. (2012). Judging the moral ambience by physical cues in an environment. Unpublished manuscript.

Motyl, M., \& Pyszczynski, T. (2010). The existential underpinnings of the cycle of terrorist and counterterrorist violence and pathways to peaceful resolutions. International Journal of Social Psychology, 22, 267-291.

Motyl, M., Vail III, K. E., \& Pyszczynski, T. (2009). Waging terror: Psychological motivations in cultural violence and peacemaking. In M. Morgan and P. Zimbardo (Eds.), The Day That Changed Everything: The Impact of 9/11 (pp. 23-36). Boston, MA:

Praeger/Greenwood Press.

Mutz, D. C. (1992). Impersonal influence: Effects of representations of public opinion on political attitudes. Political Behavior, 14, 89-122.

Mutz, D. C. (2006). Hearing the other side: Deliberative versus participatory democracy. New York, NY: Cambridge University Press.

Oishi, S. (2010). The psychology of residential mobility: Implications for the self, social relationships, and well-being. Perspectives on Psychological Science, 5, 5-21.

Oishi, S., \& Graham, J. (2010). Social ecology: Lost and found in psychological science. Perspectives on Psychological Science, 5, 356-377.

Pelled, L. H. (1996). Demographic diversity, conflict, and work group outcomes: An intervening process theory. Organization Science, 7, 615-631. 
Philbreck, N. (2007). Mayflower: A story of courage, community, and war. New York, NY: Penguin USA.

Prior, M., \& Lupia, A. (2008). Money, time, and political knowledge: Distinguishing quick recall and political learning skills. American Journal of Political Science, 52, 168-182.

Putnam, R. D. (2000). Bowling Alone: The Collapse and Revival of American Community. New York: Simon \& Schuster.

Putnam, R. D. (2007). E Pluribus Unum: Diversity and community in the twenty-first century: The 2006 Johan Skytte Prize Lecture. Scandinavian Political Studies, 30, 137-174.

Pyszczynski, T., Greenberg, J., \& Solomon, S. (1997). Why do we need what we need? A terror management perspective on the roots of human social motivation. Psychological Inquiry, 8, 1-21.

Pyszczynski, T., Motyl, M., \& Abdollahi, A. (2009). Righteous violence: Killing for god, country, freedom, and justice. Behavioral Sciences of Terrorism and Political Aggression, 1, 12-39.

Rasinski, K. A. (1987). What's fair is fair-Or is it? Value differences underlying public views about social justice. Journal of Personality and Social Psychology, 53, 201.

Rentfrow, P. J., Gosling, S. D., \& Potter, J. (2008). A rheory of the emergence, persistence, and expression of geographic variation in psychological characteristics. Perspectives on Psychological Science, 3, 339-369.

Riskind, R. G. (2012). Social climates surrounding U.S. sexual minority individuals, 2000 to present. Unpublished database.

Rosenbaum, M. E. (1986). The repulsion hypothesis: On the nondevelopment of relationships. Journal of Personality and Social Psychology, 51, 1156. 
Rutchick, A. M., Smyth, J. M., \& Konrath, S. (2009). Seeing red (and blue): Effects of electoral college depictions on political group perception. Analyses of Social Issues and Public Policy, 9, 269-282.

Schimel, J., Hayes, J., Williams, T., \& Jahrig, J. (2007). Is death really the worm at the core? Converging evidence that worldview threat increases death-thought accessibility. Journal of Personality and Social Psychology, 92, 789.

Schmitt, E. (2001, August 6). Census data show a sharp increase in living standard. New York Times. Retrieved October 1, 2012 from http://www.nytimes.com/2001/08/06/national/06CENS.html

Schmitt, M. T., Davies, K., Hung, M., \& Wright, S. C. (2010). Identity moderates the effects of Christmas displays on mood, self-esteem, and inclusion. Journal of Experimental Social Psychology, 46, 1017-1022.

Seyle, D. C., \& Newman, M. L. (2006). A house divided? The psychology of red and blue America. American Psychologist, 61, 571-580.

Shaw, M., \& Zárate, M. A. (2007). Stereotypes and prejudice in conflict: Representations of Arabs in Israeli Jewish society. Political Psychology, 28, 375-378.

Sheldon, K. M., \& Bettencourt, B. A. (2010). Psychological need-satisfaction and subjective well-being within social groups. British Journal of Social Psychology, 41, 25-38.doi: $10.1348 / 014466602165036$

Sherif, M. (1966). Group conflict and cooperation: The Robber's cave experiment.

Sinclair, S., Hardin, C. D., \& Lowery, B. S. (2006). Self-stereotyping in the context of multiple social identities. Journal of Personality and Social Psychology, 90, 529. 
Sowell, T. (2007). A conflict of visions: Ideological origins of political struggles. Basic Books: New York, NY.

Tompkins, S. (1965). The psychology of being right-and left. Society, 3, 23-27.

Vail, K. E., Arndt, J., Motyl, M., \& Pyszczynski, T. (in press). The aftermath of destruction: Images of destroyed buildings increase support for war, dogmatism, and death thought accessibility. Journal of Experimental Social Psychology.

Van Knippenberg, D., \& Schippers, M. C. (2007). Work group diversity. Annual Review of Psychology, 58, 515-541.

Walton, G. M., \& Cohen, G. L. (2011). A brief social-belonging intervention improves academic and health outcomes of minority students. Science, 331, 1447-1451.

Weigant, C. (2008, October 8). Electoral math - Obama landslide? Huffington Post. Retrieved May 10, 2012 from http://www.huffingtonpost.com/chris-weigant/electoral-math---obama-1_b_133135.html

Werner, C., \& Parmelee, P. (1979). Similarity of activity preferences among friends: Those who play together stay together. Social Psychology Quarterly, 62-66.

Winstanley, A., Thorns, D. C., \& Perkins, H. C. (2003). Nostalgia, community and new housing developments: a critique of new urbanism incorporating a New Zealand perspective. Urban Policy and Research, 21, 175-189. 
Table 1

Summary of separate logistic regressions for each political ideology predicting migration from origin community vote percentage for Senator McCain

\begin{tabular}{lccccccc}
\hline \multicolumn{1}{l}{} & $B$ & SE & Wald & Exp $(B)$ & $\begin{array}{c}95 \% \\
\text { Confidence } \\
\text { Interval }\end{array}$ & Nagelkerke's $R^{2}$ & $N$ \\
\hline Strongly Liberal & 0.46 & 0.008 & 2949.78 & 1.59 & $1.585-1.595$ & 0.17 & 152530 \\
Liberal & 0.34 & 0.006 & 2887.38 & 1.41 & $1.406-1.415$ & 0.13 & 247952 \\
Slightly Liberal & 0.22 & 0.009 & 557.41 & 1.24 & $1.235-1.245$ & 0.08 & 104807 \\
Neutral/Moderate & -0.06 & 0.006 & 125.44 & 0.94 & $0.934-0.945$ & 0.04 & 244706 \\
Slightly Conservative & -0.48 & 0.01 & 2408.71 & 0.62 & $0.611-0.629$ & 0.11 & 89676 \\
Conservative & -0.56 & 0.008 & 4703.95 & 0.57 & $0.560-0.580$ & 0.14 & 122634 \\
Strongly Conservative & -0.56 & 0.013 & 1942.41 & 0.58 & $0.56-0.590$ & 0.13 & 47703 \\
\hline
\end{tabular}

Note. All regressions models are significant, $p \mathrm{~s}<1.0 \times 10^{-7}$. 
Table 3

Correlations Between Measured Variables in Study 2

\begin{tabular}{|c|c|c|c|c|c|c|c|}
\hline & & 1 & 2 & 3 & 4 & 5 & 6 \\
\hline \multirow{6}{*}{$\begin{array}{l}\text { Overall } \\
\mathrm{n}=1236 \\
\mathrm{CI}=+/-.04\end{array}$} & 1. Current ZIP Obama Vote $\%$ & & $.40 * *$ & $.63 * *$ & $.46^{* *}$ & $.25 * *$ & $-.16 * *$ \\
\hline & 2. Previous ZIP Obama Vote $\%$ & & . & $.40 * *$ & $.17 * *$ & $.05^{*}$ & $-.07 *$ \\
\hline & 3. Actual Fit & & & . & $.52 * *$ & $.25 * *$ & $-.27 * *$ \\
\hline & 4. Perceived Fit & & & & . & $.43 * *$ & $-.30 * *$ \\
\hline & 5. Sense of Belonging & & & & & . & $-.57 * *$ \\
\hline & 6. Desire to Migrate & & & & & & . \\
\hline \multirow{7}{*}{$\begin{array}{l}\text { Liberals } \\
n=896 \\
C I=+/-.06\end{array}$} & & 1 & 2 & 3 & 4 & 5 & 6 \\
\hline & 1. Current ZIP Obama Vote $\%$ & & $.38 * *$ & $.93 * *$ & $.62 * *$ & $.35 * *$ & $-.22 * *$ \\
\hline & 2. Previous ZIP Obama Vote $\%$ & & . & $.38 * *$ & $.24 * *$ & $.10 * *$ & $-.09 *$ \\
\hline & 3. Actual Fit & & & . & $.60 * *$ & $.35 * *$ & $-.22 * *$ \\
\hline & 4. Perceived Fit & & & & . & $.52 * *$ & $-.32 * *$ \\
\hline & 5. Sense of Belonging & & & & & . & $-.57 * *$ \\
\hline & 6. Desire to Migrate & & & & & & . \\
\hline \multirow{6}{*}{$\begin{array}{l}\text { Moderates } \\
\mathrm{n}=150 \\
\mathrm{CI}=+/-.15\end{array}$} & & 1 & 2 & 3 & 4 & 5 & 6 \\
\hline & 1. Current ZIP Obama Vote $\%$ & - & $.44 * *$ & & $.35 * *$ & $.17 *$ & $-.05 *$ \\
\hline & $\begin{array}{l}\text { 2. Previous ZIP Obama Vote } \% \\
\text { 3. Actual Fit }\end{array}$ & & . & . & $.17 *$ & -.001 & -.09 \\
\hline & 4. Perceived Fit & & & & . & $.35 * *$ & $-.25 * *$ \\
\hline & 5. Sense of Belonging & & & & & . & $-.59 * *$ \\
\hline & 6. Desire to Migrate & & & & & & . \\
\hline \multirow{6}{*}{$\begin{array}{l}\text { Conservatives } \\
\mathrm{n}=190 \\
\mathrm{CI}=+/-.12\end{array}$} & & 1 & 2 & 3 & 4 & 5 & 6 \\
\hline & 1. Current ZIP Obama Vote $\%$ & & $.39 * *$ & & $-.37 * *$ & $-.14 *$ & .07 \\
\hline & $\begin{array}{l}\text { 2. Previous ZIP Obama Vote } \% \\
\text { 3. Actual Fit }\end{array}$ & & . & & $-.15 *$ & -.07 & .01 \\
\hline & 4. Perceived Fit & & & & . & $.33 * *$ & $-.23 * *$ \\
\hline & 5. Sense of Belonging & & & & & . & $-.57 * *$ \\
\hline & 6. Desire to Migrate & & & & & & . \\
\hline
\end{tabular}

Note. $* p<.05$

$* * p<.01$

$C I=95 \%$ Confidence Interval computed for the overall sample, and separately for each subgroup of the sample using the different sample sizes. 
Table 4

Intercorrelations between measured variables in Studies 3 and 4

1. Perceived Fit

\begin{tabular}{cccccc} 
& Study $\mathbf{3}$ & \multicolumn{3}{c}{ Study $\mathbf{4}$} \\
\hline 1 & 2 & 3 & 1 & 2 & 3 \\
\hline. & $.34^{*}$ & $-.28^{*}$ &. & .10 & -.17 \\
&. & $-.62^{*}$ & &. & $-.53 *$
\end{tabular}

2. Sense of Belonging

.

3. Desire to Transfer

Note. $* p<.001$. Study 3's 95\% confidence interval around the correlations is $+/-.32$. Study 4's $95 \%$ confidence interval around the correlations is $+/-.36$. 


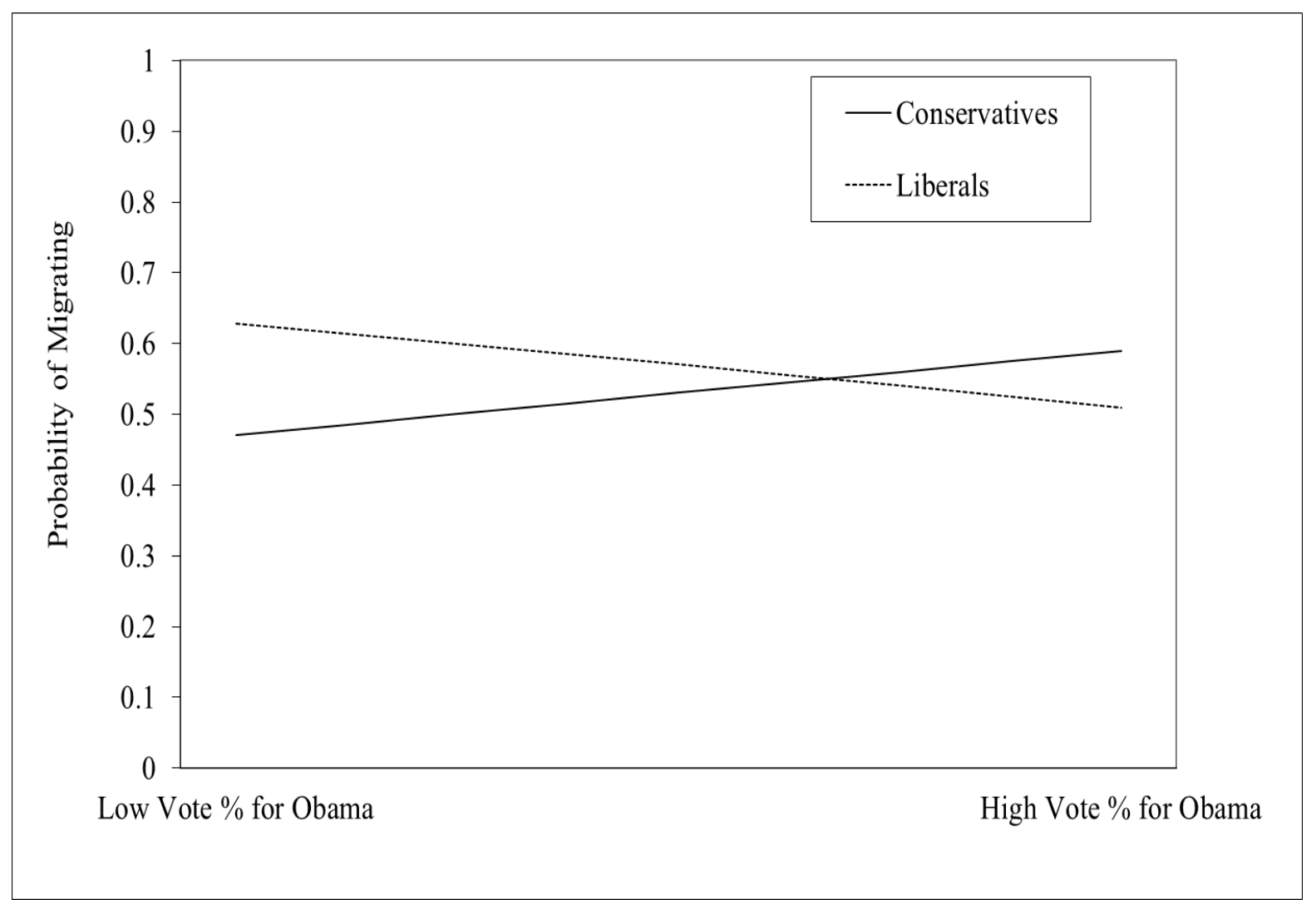

Figure 1. Probability of moving for liberals and conservatives as a function of the actual vote percentage for President Obama in their zip code (+/- $1 S D$ projected means). 


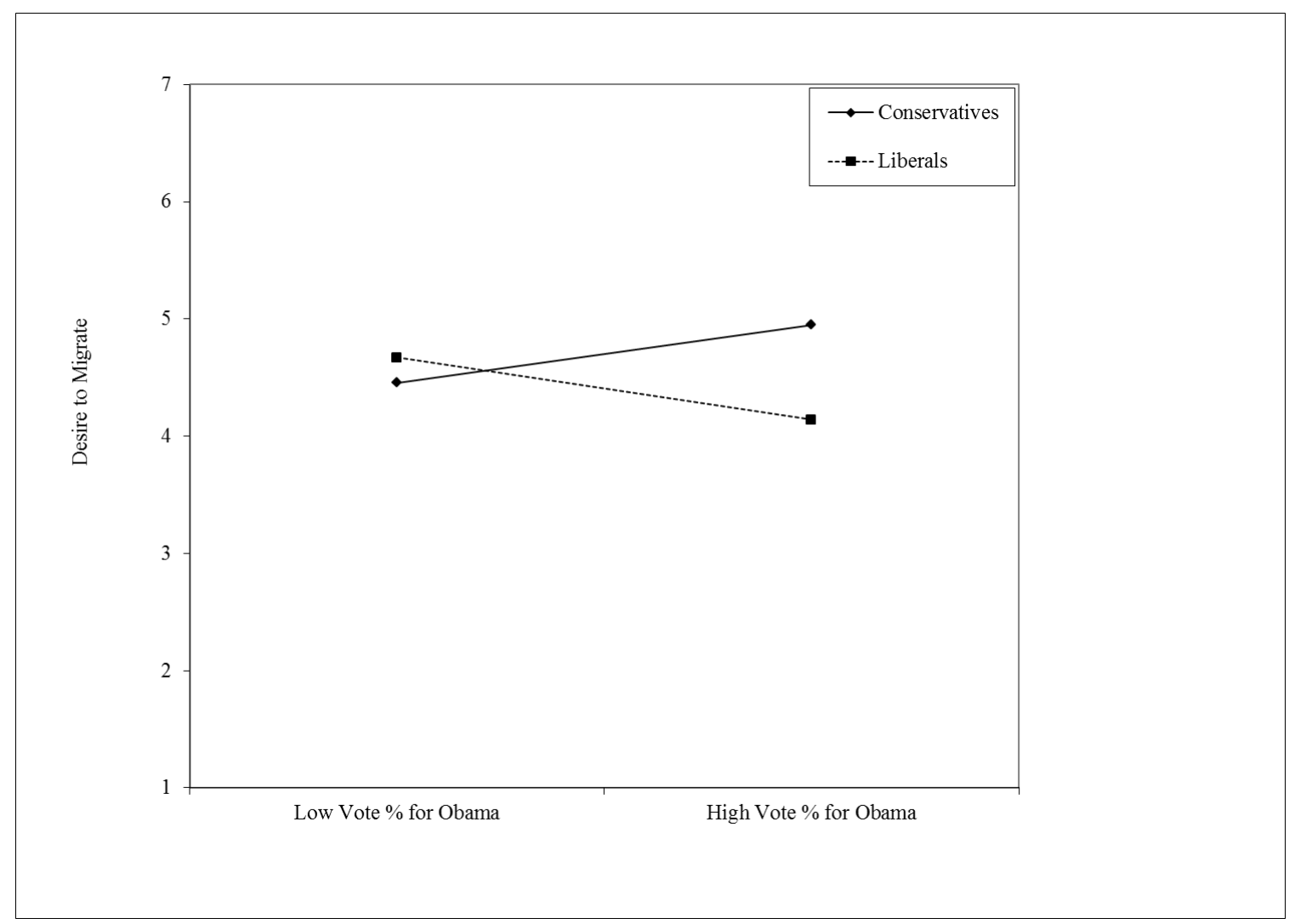

Figure 2. Liberals and conservatives desire to migrate as a function of the actual vote percentage for President Obama in their zip code (+/- $1 S D$ projected means). 


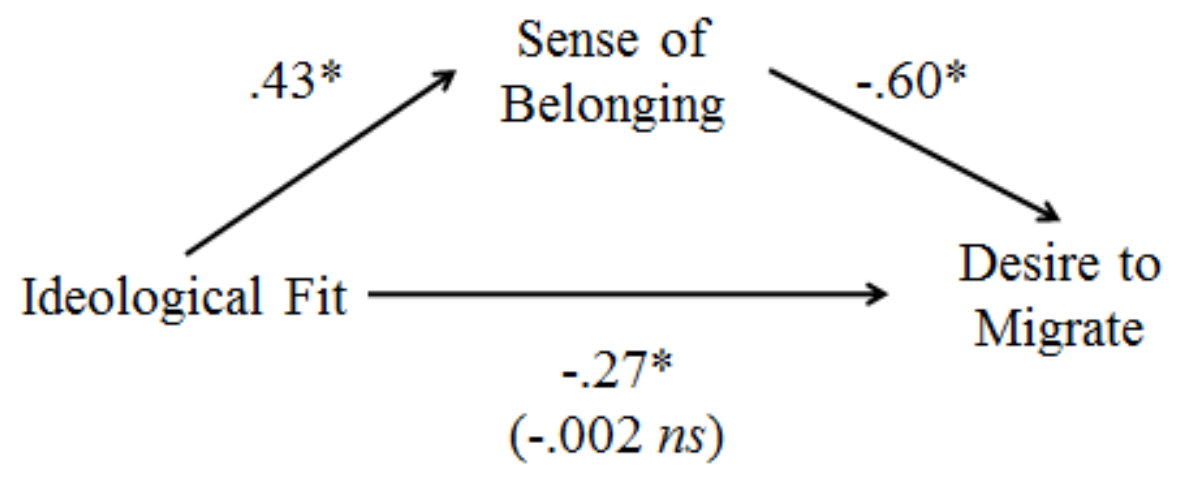

Figure 3. Sense of belonging mediates the relationship between ideological fit and desire to migrate. 


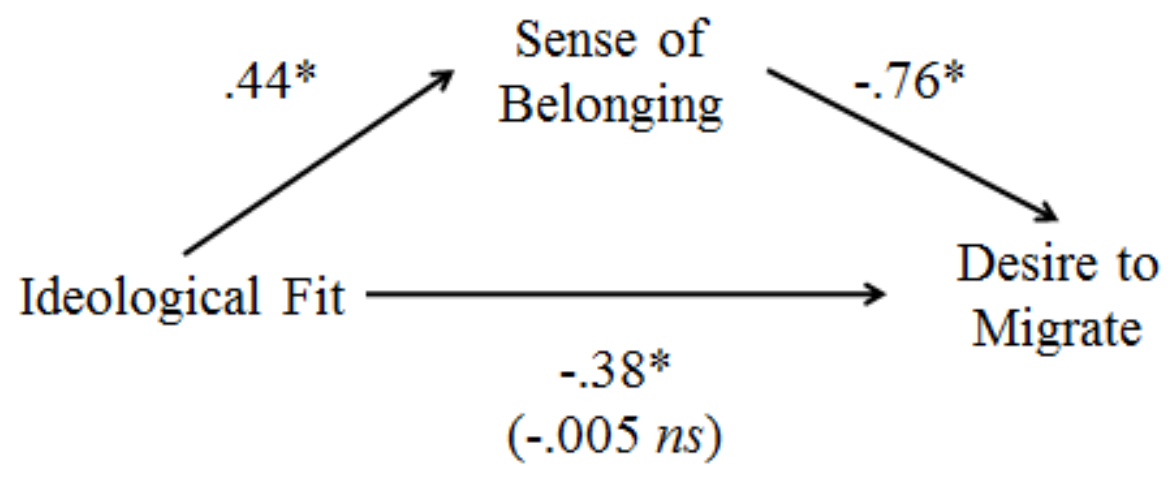

Figure 4. Sense of belonging mediates the relationship between ideological fit and desire to migrate. 


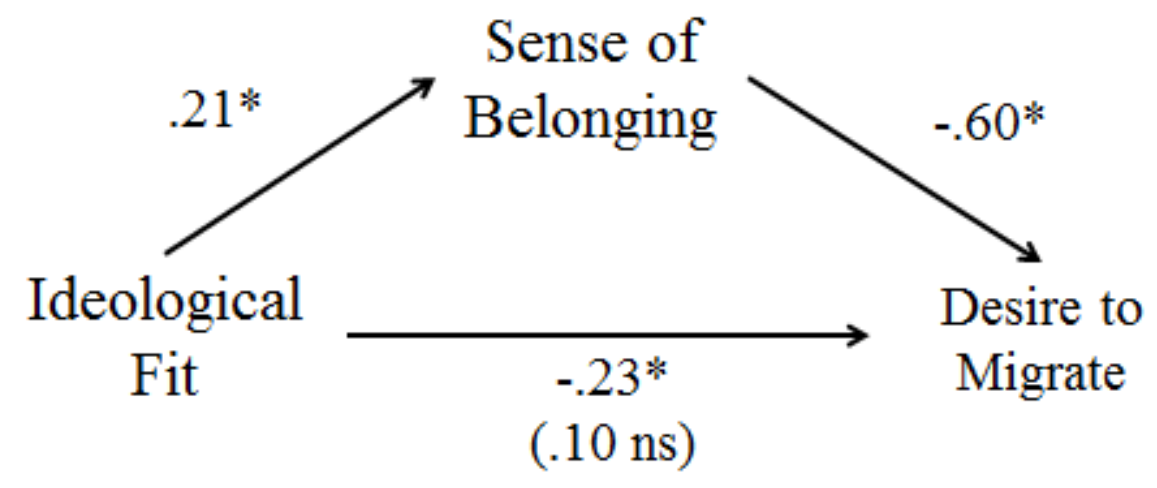

Figure 5. Sense of belonging mediates the relationship between ideological fit and desire to migrate. 